\title{
Frustration, Examination, Appreciation: An Autoethnography of a Psychotherapist's Work with a Challenging Patient
}

\section{June Tyson, LCSW, PhD}

Psychotherpist, Clinical Social Work/Therapist, 21 Saint James Place, Brooklyn, NY 11205, United States.

\author{
Article Details \\ Article Type: Case Report \\ Received date: $26^{\text {th }}$ April, 2021 \\ Accepted date: $25^{\text {th }}$ May, 2021 \\ Published date: $28^{\text {th }}$ May, 2021
}

"Corresponding Author: June Tyson, LCSW, PhD, Psychotherpist, Clinical Social Work/Therapist, 21 Saint James Place, Brooklyn, NY 11205, United States. E-mail: junetyson@gmail.com

Citation: Tyson, J. (2021). Frustration, Examination, Appreciation: An Autoethnography of a Psychotherapist's Work with a Challenging Patient. J Ment Health Soc Behav 3(1):142. https://doi.org/10.33790/jmhsb1100142

Copyright: $\mathbb{C} 2021$, This is an open-access article distributed under the terms of the Creative Commons Attribution License 4.0, which permits unrestricted use, distribution, and reproduction in any medium, provided the original author and source are credited.

\section{Introduction}

What the doctor fails to see in himself, he will either not see at all in his patient, or see grossly exaggerated.

\section{--C.G.Jung}

The work of a psychotherapist can be rewarding and very challenging. It can be frustrating when patients are suffering and there are no words to alleviate their pain, or when they begin to take their anger out on you as a therapist. The work of a psychotherapist can be a personal beneficial experience as one examines how one is affected as a professional because of a seemingly difficult and challenging patient. The work of psychotherapy can also bring about a sense of appreciation as psychotherapists learn to appreciate their own delicate individual growth because of a challenging patient.

\section{Background to the Problem}

Research states that there are times when psychotherapists' interests appear to outweigh the ultimate goal of the work: helping patients. Mohr [1] stated that psychotherapists tend to shy away from looking at negative outcomes of cases. Negative outcomes of cases are seldom reported due to psychotherapists'reluctance to examine failures. Mohr [1] went on to state that some of us neglect to ask of ourselves what we ask of our patients, which is to examine our failings with an open mind and a view toward change. This paper is an autoethnographical account of a psychotherapist's (my) experience of a case that was particularly challenging and making the best of the experience. The purpose of this article is to demonstrate how a psychotherapist can get the most from his or her work and grow as a result of being challenged by his or her patients. This article shows how I went through the process of frustration, examination, and appreciation and used the process as a tool to become more effective in my work with all of my patients.

\section{The Positive Psychology Movement}

Seligman is a pivotal figure in the field of positive psychology, having challenged others to embrace research related to positive psychology. This was a paradigm shift for psychologists who traditionally focused on mental health deficits and problems to mental health strengths and the ways that people can thrive. He is the director of the Positive Psychology Center at the University of Pennsylvania. The Positive Psychology Movement is the scientific study of the strengths and virtues that enable individuals and communities to thrive. Positive psychology has identified six virtues, which are considered superior by the vast majority of cultures throughout history: wisdom and knowledge, courage, humanity, justice, temperance, and transcendence. Positive psychology has identified six virtues, which are considered superior by the vast majority of cultures throughout history: wisdom and knowledge, courage, humanity, justice, temperance, and transcendence. Positive psychology research indicates that these virtues lead to increased happiness when practiced and contribute to healing [2]. Through this article, I show how these virtues of positive psychology assisted in my growth as a professional regarding this challenging case.

\section{Rationale, Relevance, and Significance of the Study}

Najavits [2] stated that few psychotherapists can confront patients in a compassionate way, give feedback that will promote growth, manage aggression, bring out the most hidden feelings and thoughts, and hold patients accountable to do their best. It is the hope and desire of every true psychotherapist to be able to practice in this way and empower patients. This article demonstrate show this goal was achieved as I went through the process of frustration, examination, and appreciation. This personal individual process of psychotherapists has the potential to bring healing to the patient and the professional.

\section{Nature of the Study}

Autoethno graphy is an emerging qualitative research method that allows the author to write in a highly personalized style, drawing on his or her experiences to extend understanding about a phenomenon. Sparkes [4] stated that autoethno graphies are private accounts that draw from the experiences of the author/researcher for the purpose of extending sociological understanding. I used this methodology to express how I progressed and developed in my practice and how it helped me to provide a beneficial service to my patients.

\section{Literature Review}

\section{Early Formation of Countertransference}

Countertransference is a major reason why psychotherapists have challenges with patients. Sigmund Freud first defined countertransference in 1910 in The Future Prospects of Psychoanalytic Therapy. Freud stated that since an analyst is a human himself, he could easily let his emotions into the client. This information warns professionals against the dangers of countertransference and encourages them to master it in themselves. In cases of countertransference, the patient represents for the psychotherapist an object of the past onto whom past feelings and wishes are projected.

Countertransference includes unconscious reactions to a patient that are determined by the psychotherapist's own life history. It was later expanded to include unconscious hostile feelings toward a patient that interfere with objectivity and limit the psychotherapist's effectiveness. For example, a psychotherapist might have a strong desire for a client to do very well in sports because the client reminds 
the psychotherapist of his or her children at that stage in life and the anxieties the psychotherapist experienced during that time.

\section{Countertransference in the Twentieth Century}

Positive views of countertransference were accepted as the 20th century progressed. Its definition began to include the understanding of the entire body of feelings the therapist has toward the patient. According to Sedgwick [5], Jung explored the importance of the therapist's reaction to the patient through the image of the wounded healer, meaning it is the psychotherapist's own hurt that gives the measure of his power to heal. Heimann [6] stated that the psychotherapist's countertransference is not only part and parcel of the analytic relationship, but it is the patient'screation. Various parts of the patient's personality bring out the countertransference in the psychotherapist.

The contemporary understanding of countertransference views it as a jointly created phenomenon between the psychotherapist and the patient. The patient pressures the psychotherapist through transference to play a role in the patient's internal world. However, the specific dimensions of that role are colored by the psychotherapist's own personality [7]. Countertransference can be a therapeutic tool when examined by the psychotherapist to sort out who is doing what, and the meaning behind those actions. Psychotherapists should continue to be aware of the serious risks of unresolved countertransference being acted out within what is meant to be a therapeutic relationship [8].

\section{Countertransference Today}

Countertransference has had increased recognition in the $21 \mathrm{st}$ century. Grotstein [9] indicated that most countertransference reactions are a blend of the two aspects, personal and diagnostic, which require careful disentanglement in their interaction. It is possible that now adays psychotherapists use countertransference over the years [10]. One reason for this shift might be that because in object relations therapy, the relationship is very central; countertransference reactions are considered key in helping the psychotherapist to understand the transference [11].

\section{Positive Psychology}

This article was grounded in positive psychology theory. I used this theory to assist me in processing my feelings when dealing with the challenging patient. These feelings are described later. Positive psychology is the study of the strengths and virtues that enable individuals, groups, and communities to thrive. Peterson and Seligman [12] developed the Character Strengths and Virtues Handbook, which classifies strengths and virtues as having the following characteristics: wisdom and knowledge, courage, humanity, justice, temperance, and transcendence. According to Seligman [2], these human qualities enable a person's resiliency.

\section{Wisdom and Knowledge}

Possessing wisdom and knowledge means having a deep understanding of people, things, events, or situations. It is an attribute that is developed over time. It empowers one with the ability to choose or act to consistently to produce the optimum results with a minimum of time and energy [13].

\section{Courage}

Courage, also known as bravery, fortitude, will, and intrepidity, is the ability to confront fear, pain, risk/danger, uncertainty, or intimidation. Courage is required to be able to face the fact that a psychotherapist is experiencing challenges from a patient and that the psychotherapist's own countertransference may be adding to the challenge. Because fear can be an immobilizing, hindering factor when attempting to make progress, it will take courage to overcome the various elements of fear. The person who has courage will much more than transference another interesting shift in perspective

have the ability to do the things a wise person does, as mentioned previously.

\section{Humanity}

Humanity is the quality of being humane, kind, and benevolent. There is a certain degree of humanity in a person who has chosen psychotherapy as a career. The desire to assist others in learning and growing from their challenges requires kindness and compassion.

\section{Temperance}

The Cambridge Dictionary (n.d.) [14] defines temperance as control of one's own behavior, such as not drinking or eating too much. Psychotherapists can use this virtue. The virtue of temperance has the ability to provide structure, discipline, and restraint as a psychotherapist deals with a challenging patient.

\section{Justice}

Justice is the concept of moral rightness based on ethics, rationality, law, natural law, religion, fairness, and equity [15]. This view of justice can be helpful to a person in creating meaning from handling a challenging patient. A sense of justice can assist the psychotherapist in responding in a manner that is fair to the patient and to him- or herself.

\section{Transcendence}

Transcendence is climbing or going beyond some philosophical concept or limit. The psychotherapist dealing with a challenging patient can transcend negative effects and choose to make the process a healing one. Expressed hurt feelings can be worked with and released, which entails moving through the pain thoughtfully and deliberately and thus transcending it. Seligman [12] stated that one of the main objectives of positive psychology is to study the human capacity to create order and meaning in response to inevitable adversity.

\section{The Gift of Gratitude}

Emmons [16], a leading scholar in positive psychology, is a trailblazer in the study of gratitude and how gratitude positively impacts the capacity to handle the various challenges of life. Gratitude serves an important purpose because it shifts our focus off ourselves when overwhelmed by our own emotions [16]. This article show show gratitude played a role in my desire to create meaning from the experience of dealing with a challenging patient.

Research has demonstrated the strong role that gratitude plays with heart attack victims. Those who placed the blame of the heart attack on other people or circumstances were more likely to suffer another heart attack within the next eight years [17]. However, heart attack victims who created meaning in their loss of health by becoming more appreciative of life and feeling gratitude for having survived had a reduced risk for a subsequent attack. Thus, feelings of gratitude when dealing with a challenging patient can produce growth in a psychotherapist, making him or her more productive and effective.

\section{Methodology}

As stated previously, the purpose of this article is to demonstrate how a psychotherapist can get the most from his or her work and grow as a result of being challenged by his or her patients. In doing so, I reflect on my feelings of frustration as well as the process of examination and appreciation as I treated a challenging patient. The authoethnographical approach is the method used to illustrate the process of growth and professionalism.

According to Maréchal [18], "Autoethnography is a method of research that involves self-observation and reflexive investigation in the context field work and writing" (p.43). The researcher shares his or her own personal thoughts, feelings, stories, and observations as a way of understanding the social context being studied. In doing this, autoethno graphers also shed light on their total interaction with 
that setting by making their every emotion and thought visible to the reader.

\section{Data Collection}

Autoethno graphical methods include journaling, looking at archival records whether institutional or personal interviewing oneself, and using writing to generate a self-cultural understanding. For this article, I used a diary I kept about a particularly challenging patient. I made weekly entries in the diary for one year. The diary recorded the feelings the patient evoked in me as I practiced psychotherapy. There is no identifiable information about the patient in the diary.

According to Bochner et al. [19], an autoethnographer assumes the roles of communicator and story teller. In other words, autoethno graphy "depicts people struggling to overcome adversity [and shows] people in the process of figuring out what to do, how to live, and the meaning of their struggles" [19] (p.111). Therefore, this article illustrates the emotions involved in the process of evolving as a professional and an individual,because of treating a challenging patient.

\section{Evaluating Autoethnographical Research}

Ellis et al. [20] discussed how to evaluate an autoethnographical project, based on other authors' ideas about evaluating alternative modes of qualitative research. Her suggestions are as follows:(a) substantive contribution; does the piece contribute to our understanding of social life? (b) aesthetic merit; does this piece succeed aesthetically? Is the text artistically shaped, satisfyingly complex, and not boring? (c) reflexivity; how did the author come to write this text? How has the author's subjectivity been both a producer and a product of this text? (d) impactfulness; does this affect me emotionally and/or intellectually? Does it generate new questions or move me to action? (e) expresses a reality; does this text embody a fleshed-out sense of lived experience?

\section{From "Validity" to "Truth"}

Ellis [20] wrote, "In autoethnographic work, I look at validity in terms of what happens to readers as well as to research participants and researchers. To me, validity means it evokes in readers a feeling that the experience described is life like, believable, and possible. You also can judge validity by whether it helps readers communicate with others different from themselves or offers a way to improve the lives of participants and readers or even your own" (p.124). In this sense, Ellis [20] emphasized the "narrative truth" for autoethnographical writings. For this article, I hope to impart the truth of my feelings as I moved from frustration to appreciation of my work with a challenging patient.

\section{Reflexivity and Voice}

Just writing was like therapy for me.

--Justin Timberlake

Following is a summary of excerpts from my diary about a challenging patient. The patient seemed nice and pleasant in the first few sessions. The patient had no previous experience with psychotherapy and was not on medication. At the time, the patient was very depressed about various issues he had experienced.

The patient seems to be stuck on one particular issue and is constantly asking for my advice. I do not usually give advice. I will just have to do what I usually do with patients asking for advice: ask them what seems best for them to do. The patient responds in a mature manner and wants to do what is just and fair. I encourage and support the patient for the decision.

For months, the patient is resolved to stick to the decision made. This goes on for a exactly 7 months actually. As I encourage and support the patient, I thought the therapeutic relationship was becoming comfortable and healthy.
The patient does not have a lot of support, so my work and I are greatly appreciated. As the patient begins to praise me during and after each session, I feel uncomfortable. It just seems to be too much and overdone words like "you are wonderful," "I don't know what I'd do without you," "I can't believe that I have had to go through life for so long without your help."I have been trying to refocus the patient to recognize his own personal strengths, which have been a great assist in making him feel better, but the patient always seems to end up giving me the credit for his newly restored hope. I don't like this.

As we continue like this, I am becoming more and more uncomfortable, annoyed, and aggravated with the patient because his view of our relationship is now becoming imbalanced and distorted. My efforts to maintain balance, reality, and truth to the therapeutic relationship are to no avail. The patient is beginning to ask me personal questions and wanting to know what I would do in a particular situation. I realize that it is natural for patients to be curious about their psychotherapist, but my feelings of frustration with the patient are making me irritated and aggravated. I felt like the patient was trying to get into my psyche and trying to be able to read me.

As I try to explain to the patient that his praising and focusing too much on me, instead of realizing his own strengths and his feelings of curiosity about my personal life is natural but has no real relevance to his life, the patient suddenly becomes incensed. This occurred abruptly and I was very surprised at this reaction. The patient stood up and began yelling about opening up about his life and how I was not willing to be forth coming about my life. The patient yelled at me, did not allow me to speak and get my point across at all. The patient did not come to session for two weeks after this incident and I was glad because I was very frustrated with the patient. The patient's absence also gave me a chance to process my feelings.

\section{Frustration}

I was livid! I was shocked and very confused. I was embarrassed. I felt this patient disrespected me and my office. I doubted my ability as a psychotherapist because I was not able to foresee this outburst. I did not see any signs that this would happen.

I was very angry with this patient. Actually I did not want the patient to ever return. Frustration was the only feeling I experienced whenever I even thought about the patient. Nevertheless, after a while, I was able see the issue from a different perspective.

\section{Examination}

Frustration, although quite painful at times, is a very positive and essential part of success. I knew that I had to learn from this experience instead of allowing it to get the best of me. It is very important to me to be the best psychotherapist that I can be. If I truly loved the profession and cared for my patients, then I knew I had to do something that is very difficult for me. I decided to look deep inside myself for answers. What can I learn from this experience?

This situation stirred up my personal issues of not being heard, not listened to, not given a chance to explain myself, being "talked over," and my insecurities about my feelings and thoughts are not important. This was the most painful part of the experience. I have always loathed not being given a chance to express myself during a conflict.

This feeling is so deeply implanted in me that I often have dreams about people ignoring me when I am trying to say something very important and crucial to a certain situation. It was evident that during this, I was experiencing feelings of countertransference due to my history and insecurities about not being heard. It was not easy to be so honest with myself.

My countertransference did not allow me to see this issue as it truly was. There was a hidden purpose of our confrontation that was over shadowed by the feelings we were experiencing on the surface. 
I truly believe this issue occurred to give us both a chance to look at ourselves and confront parts of our personalities that are difficult to face.

\section{Appreciation}

I also keep a section in my journal to express my feelings of gratitude and appreciation about my experiences with patients. A gratitude journalis adiary of things for which one is grateful. Gratitude journals are used by individuals who wish to focus their attention on the positive things in their lives, and I wanted to make this a positive experience. This section of my journal helped me to process the benefits of this experience along with my feelings of countertransference.

As I worked through my countertransference, I began to see parts of myself that I tried to suppress because they were too painful to confront. [Mohr [1] said that psychotherapists sometimes neglect to ask of ourselves what we ask of our patients, which is to examine our failings with an open mind and a view toward change.] If being a helpful, nurturing psychotherapist is really my goal, then honest examination of my feelings, thoughts, history, failings, and pain is often required.

Because of this situation, I am determined to discover my true self as I work with patients that challenge me to move out of my comfort zone. I am learning to accept the fact that I have an issue with being heard and I am dealing with it in supervision. I am beginning to understand that not everyone will listen to me during a heated transaction or even during a pleasant discussion. I realize that I have to handle this predicament in a healthier manner.

[Gratitude serves an important purpose because it shifts my focus off my pain when over whelmed by my own emotions] [16]. My appreciation of this issue with the challenging patient allowed me to move my attention away from my pain and focus on how the experience can be used to benefit my patient and me. This challenge was a great learning experience for me and a benefit to my overall practice as a psychotherapist.

Eventually I called the patient to return to sessions. The patient returned apologetically and remorsefully. I used the incident as a tool for treatment as I explained the elements of transference because I was better able to understand the patient's transference because of my understanding of my countertransference.

\section{Conclusion}

\section{A Better Understanding of Transference and Countertransference}

Jacobs [21] said it is possible that now adays psychotherapists use countertransference much more than transference because in object relations therapy, the relationship is very central. In this experience, countertransference reactions were considered key in helping me to understand the transference. By examining my own countertransference, I was able to understand the patient's transference and explain how it affects his daily life. This element was very helpful because it allowed the patient to focus our attention on an important area that was not being addressed in therapy.

\section{The Benefits of Positive Psychology Theory}

I also used the elements of the positive psychology theory, as a frame work, to help process this phenomenon. Positive psychology has identified six virtues: wisdom and knowledge, courage, humanity, justice, temperance, and transcendence. These virtues lead to increased happiness when practiced and contribute to healing. I used these virtues as I processed my feelings about the challenge with my patient.

\section{Wisdom and knowledge}

I have never felt particularly wise or knowledgeable. Nevertheless, I felt the need to find wisdom and knowledge. I was able to tap into these attributes in myself as I sought to overcome my feelings of frustration and use the experience to grow as a professional.

\section{Courage}

I understood that it took courage to take an honest look at my own insecurities and discuss them in supervision. I was afraid and did not want to feel the pain of past experiences. I found it very necessary to do so as I needed to grow from this situation with my patient.

\section{Humanity}

My love for my profession and humanity at large helped me to reach out to the patient when he did not come to sessions. I did not know howI would be received. However, I wanted to grow and help the patient to grow, and this was my motivation for calling the patient back to sessions.

\section{Justice}

It would have been very unjust for meto not reach out to the patient because of my own feelings of pain. I actually considered doing this, but I rethought it. I wanted to be just and fair to the patient, the profession, and myself.

\section{Temperance}

I understood that self-control is always needed in psychotherapy. Issues of counter transference are certain to arise suddenly, unexpectedly, and the ability to control oneself and the situation is required. I realized there were other ways I could have handled this situation and myself, which could have diffused an outburst. After this issue was resolved, I did a great deal of reading about how to deal with situations such as this.

\section{Transcendence}

My feelings of appreciation helped me to transcend my feelings of frustration. I felt free and able to think clearly about my work with all my patients. I was able to see the benefits of the entire challenge to the patient, my profession, and my self as an individual.

In conclusion, I use the process of frustration, examination, and appreciation whenever I encounter a challenging patient. It allows me and the patient to grow. I am less apprehensive about confronting my own insecurities and examining them when they arise during sessions. I continue to keep a diary of my feeling and I express my gratitude in this diary as well. I believe I am a better psychotherapist as a result of this one patient who forced me to come face-to-face with myself.

In therapy, I see myself in the mirror differently.

--Ricky Williams

Conflicts of interest: The authors have no conflicts of interest to disclose.

\section{References}

1. Mohr, D.C. (2015). Negative outcome in psychotherapy: A critical review. Clinical Psychology: Science and Practice, 2, $1-24$.

2. Seligman, M. E. P. (2006). Authentic happiness. New York, NY: Free Press.

3. Najavits, L.M. (2000). Training clinicians to conduct the Seeking Safety treatment for posttraumatic stress disorder and substance abuse. Alcoholism Treatment Quarterly, 18, 83-98.

4. Sparkes, A. C. (2000). Autoethnography and narratives of self: Reflections on criteria inaction. Sociology of Sport Journal, 17, 21-43.

5. Sedgwick, D. (1993). The wounded healer: Countertransference from a Jungian perspective. New York, NY: Routledge.

6. Heimann, P. (1950). On countertransference. International Journal of Psycho-Analysis, 31,81-84. 
7. Gabbard, G. O. (2014). Commentary on papers by Tansey, Hirsch, and Davies. Psychoanalytic Dialogues, 4,203-213.

8. Casement, P. (1990).On learning from the patient. London, England: Tavistock.

9. Grotstein, J.S. (2009). But at the same time and on another level.London, England: Karnac.

10. Jacobs, M. (2016). Psychodynamic counselling in action. London, England: Sage.

11. Grant, J., \& Crawley, J. (2012). Transference and projection: Mirrors to the self. Buckingham, England: Open University Press.

12. Peterson, C., \& Seligman, M. (2004). Character strengths and virtues: A handbook and classification. New York, NY: Oxford University Press.

13. Sternberg, R. J. (1985). Beyond IQ: A triarchic theory of human intelligence. England: Cambridge University Press.

14. Temperance. (n.d.). In Cambridge dictionary. Retrieved from dictionary.cambridge.org/

15. Konow, J. (2013, December). Which is the fairest one of all? A positive analysis of justice theories. Journal of Economic Literature, 41, 1188-1239.
16. Emmons, R. A. (2017). Thanks!: How the new science of gratitude can make you happier. New York, NY: Houghton Mifflin.

17. Affleck, G. (2012). The challenge of capturing daily processes at the interface of social and clinical psychology. Journal of Social and Clinical Psychology, 21, 610-627.

18. Maréchal, G. (2010). Autoethnography. In A. J. Mills, G. Durepos,\& E. Wiebe(Eds.), Encyclopedia of case study research(Vol. 2, pp.43-45). Thousand Oaks, CA:Sage.

19. Bochner, A. P., \& Ellis, C. S. (2016). Communication as autoethnography. In G. J. Shepherd, J. S. John, \& T. Striphas (Eds.),Communication as: Perspectives on theory (pp.110-122).

20. Ellis, C. (2014).The ethnographic I: A methodological novel about autoethnography. Walnut Creek: AltaMira Press.

21. Jacobs, J.M. (2006). A geography of big things,13, https://doi. org/10.1191/1474474006eu354oa 